\title{
FACTORS DETERMINING COLORECTAL CANCER SCREENING AMONG SECONDARY SCHOOL TEACHERS IN KIRKUK CITY
}

\author{
Aynar Khaleel Shakeer ${ }^{1}$, Arkan Bahlol Naji ${ }^{2}$ * \\ 1. Kirkuk Health Directorate, Kirkuk General Hospital, City of Kirkuk, Iraq; \\ 2. Department of Community Health Nursing, College of Nursing, University of Baghdad, City of Baghdad, Iraq.
}

\section{Corresponding author: Aynar Khaleel Shakeer}

Email: arkan nagi web2009@yahoo.com

ORCID

\section{ABSTRACT \\ Study Design: A descriptive predictive design was used to guide this study.}

Study Objectives: This study to (1) identify the association between teachers' age, body mass index, years of employment, and their intention to undergo colorectal cancer screening, and (2) investigate the difference in teachers' health beliefs about colorectal cancer screening between the groups of gender, educational qualification, marital status, and family history of having colorectal cancer.

Setting: This study was conducted in secondary schools in Kirkuk City.

Sample and Sampling: The study included a convenience sample of 397 secondary school teachers.

Study Instrument: The study instrument is composed of teachers' sociodemographic sheet, the body mass index, and the Health Beliefs Scale for Colorectal Cancer Screening.

Data Collection: Data were collected using an online survey "Google form". Data were collected for the period from March 6th, 2021 to April 10th, 2021.

Study Results: There was a statistically significant positive association between participants' age and their Perceived Susceptibility of contracting colorectal cancer. On the other hand, there was a statistically significant inverse association between participants' body mass index and their Perceived Susceptibility of contracting colorectal cancer. There was a statistically significant inverse association between participants' years of employment and their Perceived Benefits of colorectal screening.

Conclusions: The student researcher recommends that there is a need to devote health promotion activities, particularly that encourage older teachers, those who are overweight and/or obese, those who have a family history of colorectal cancer, single, and have lower educational qualification to undergo colorectal screening.

Keywords: Colorectal Cancer Screening; Determining Factors

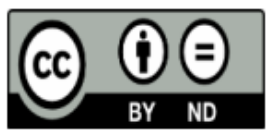

This work is licensed under a Creative Commons Attribution Non-Commercial 4.0 International License.

Received: 25 October 2021, Accepted: 06 December 2021, Available online: 20 January 2022 


\section{INTRODUCTION}

Colorectal cancer is the commonest malignancy in the gastrointestinal tract and the third leading cause of cancer associated death in the world. Usually, CRC is thought as a common disease affecting old people, with most cases diagnosed during the 5th and 6th decades and a higher prevalence among men (Campos et al., 2017).

During the past decades, there is a trend in decreasing the incidence of CRC in older people with an opposite effect among adolescents and young adults (Fancher et al., 2011), a change that has been attributed to an inadequate screening and lifestyle risk factors related to obesity and diet profile (Hubbard \& Grothey, 2013).

The overall crude incidence of colorectal cancer increased in most European countries over the last decade. The annual increase ranged in different countries between $0.4 \%$ and $3.6 \%$. The recent introduction of CRC screening in most European countries will likely reverse this trend. These screening programs typically target subjects aged 50 years and above. In several parts of the world, the CRC incidence has also risen in individuals below 50 years of age. In the USA, the incidence of colon cancer increased since 1974 with $1.0 \%$ $2.4 \%$ annually and the incidence of rectal cancer with 3.2\% (Vuik et al., 2019).

In the worldwide, nearly 800,000 new CRC cases occur each year, comprising $10 \%$ of all cancer malignancies with nearly 450,000 cases mortality annually. Totally, CRC is the fourth commonest form of cancer occurring worldwide. Furthermore, cancer incidence data and death rate in Asian countries may be underestimated (Tahmasebi et al., 2016).

In recent years, alterations in diet, sedentary lifestyles, and the rising prevalence of obesity have been hypothesized to impact molecular and physiological characteristics influencing the risk of CRCs and other cancer types in younger populations. Additional insights into the clinicopathology and speculated etiology and risk factors of early-onset colorectal cancers have been comprehensively reviewed (Loomans-Kropp \& Umar, 2019).

Global patterns vary widely and are strongly linked to human development index level, reflecting the adoption of western lifestyles that accompany economic transition and elevate risk. In general, CRC incidence is rising in low-income and middle-income countries but beginning to stabilize or decline in high-income countries, especially those that have implemented screening. However, accumulating evidence from studies of cancer registry data indicates that favorable overall trends are masking an increase in young-onset CRC in the USA, Australia and Canada (Siegel et al., 2019).

The possible reasons for this increasing incidence are unknown but may be related to the increasing prevalence of obesity, lack of exercise and to dietary factors such as alcohol and processed meat. Further-more, urbanization and pollution have been implicated in the overall increase in cancer incidence. CRC in young adults is in part due to hereditary cancer syndromes, but most cases are sporadic (Vuik et al., 2019).

Beliefs provide a crucial link between socialization and behavior. Beliefs are enduring individual characteristics that shape behavior and can be acquired through primary socialization. Beliefs are also modifiable and can differentiate between individuals from the same background. If persuasive techniques can be used to change behavior related beliefs and such interventions result in behavior change, this provides a theoretical and practical basis for evidence-based health education (Abraham, \& Sheeran, 2015).

The HBM had the advantage of specifying a discrete set of common-sense beliefs that appear to explain, or mediate, the effects of demographic variables on health behavior patterns and are amenable to change through educational intervention. The model could be applied to a range of health behavior's and so provided a framework for shaping behavior patterns relevant to public health as well as training health care professionals to work from their patients' subjective perceptions of illness and treatment. Consensus regarding the utility of the HBM was important for public health research and, simultaneously, placed cognition modelling at the center of health service research (Orji et al., 2012).

This study aims to (1) identify the association between teachers' age, body mass index, years of employment, and their intention to undergo colorectal cancer screening, and (2) investigate the difference in teachers' health beliefs about colorectal cancer screening between the groups of gender, educational qualification, marital status, and family history of having colorectal cancer.

\section{METHOD}

\section{-Study Design:}

A descriptive predictive design was used to guide this study. 


\section{-Study Objectives:}

This study to :

(1) identify the association between teachers' age, body mass index, years of employment, and their intention to undergo colorectal cancer screening.

(2) investigate the difference in teachers' health beliefs about colorectal cancer screening between the groups of gender, educational qualification, marital status, and family history of having colorectal cancer.

\section{-Study Setting:}

This study was conducted in secondary schools in Kirkuk City.

Sample and Sampling: The study included a convenience sample of 397 secondary school teachers.

\section{-Study Instrument:}

The study instrument is composed of teachers' sociodemographic sheet, the body mass index, and the Health Beliefs Scale for Colorectal Cancer Screening.

\section{-Data Collection:}

Data were collected using an online survey "Google form". Data were collected for the period from March 6th, 2021, to April 10th, 2021.

\section{Statistical analysis}

The collected data were compiled and analysed using percentages, mean, median, and Chi-square tests using SPSS version 21. $P$ values of 0.05 were used as a cut-off point for the significance of the statistical test.

\section{RESULTS}

Table 1 shows the mean age is $40.14 \pm 6.57$; most age 35-43-years $(n=308 ; 77.6 \%)$, followed by those wo age 44-52-years $(n=56 ; 14.1 \%)$, and those who age 53-62-years $(n=33 ; 8.3 \%)$.

Concerning gender, most are females $(n=257$; $64.7 \%$ ) compared to males ( $n=140 ; 35.3 \%$ ). Regarding marital status, most are married $(\mathrm{n}=$ $287 ; 72.3 \%$ ), followed by those who are Widows/Widowers $(n=65 ; 16.4 \%)$, those who are divorced $(n=30 ; 7.5 \%)$, and those who are not married $(n=15 ; 3.8 \%)$.
Regarding family's monthly income, around twofifth reported that their family monthly income ranges between $601.000-900.000(n=158$; $39.8 \%$ ), followed by those whose monthly income ranges between $901.000-1.200 .000(n=100$; $25.2 \%$ ), those whose monthly income is 1.501 .000 or higher $(n=60 ; 15.1 \%)$, those whose monthly income ranges between $300.000-600.000(n=48$; $12.1 \%$ ), and those whose monthly income ranges between $1.201 .000-1.500 .000(n=31 ; 7.8 \%)$.

Table 2 shows there is a statistically significant positive association between participants' age and their Perceived Susceptibility of contracting colorectal cancer $(r=0.01)$. On the other hand, there is a statistically significant inverse association between participants' body mass index and their Perceived Susceptibility of contracting colorectal cancer $(r=0.05)$.

Table 3 shows there is a statistically significant inverse association between participants' years of employment and their Perceived Benefits of colorectal screening $(r=0.01)$. On the other hand, there is a statistically significant positive association between participants' body mass index and their Perceived Benefits of colorectal screening $(r=0.01)$.

Table 4 shows there are statistically significant differences subjects' Perceived Susceptibility of contracting colorectal cancer and Perceived Benefits of colorectal screening between the groups of gender $(p=0.01,0.01)$ respectively.

Table 5 shows there are statistically significant differences in subjects' Perceived Susceptibility of contracting colorectal cancer and Perceived Benefits of colorectal screening between the family history of colorectal cancer $(p=0.05,0.01)$ respectively.

Table 6 shows there are statistically significant differences in subjects' Perceived Barriers to colorectal screening, Perceived Susceptibility of contracting colorectal cancer, and Perceived Benefits of colorectal screening among the marital status groups $(p=0.01,0.01,0.01)$ respectively.

Table 6 shows there are statistically significant differences in subjects' Perceived Barriers to colorectal screening and Perceived Benefits of colorectal screening among the educational qualification groups $(p=0.01,0.01)$ respectively. 
Table 1. Participants' sociodemographic characteristics $(\mathrm{N}=397)$

\begin{tabular}{|c|c|c|}
\hline Variable & Frequency & Percent \\
\hline \multicolumn{3}{|l|}{ Age (Years): Mean (SD) $=40.14 \pm 6.57$} \\
\hline $35-43$ & 308 & 77.6 \\
\hline $44-52$ & 56 & 14.1 \\
\hline $53-62$ & 33 & 8.3 \\
\hline \multicolumn{3}{|l|}{ Gender } \\
\hline Male & 140 & 35.3 \\
\hline Female & 257 & 64.7 \\
\hline \multicolumn{3}{|l|}{ Marital Status } \\
\hline Not married & 15 & 3.8 \\
\hline Married & 287 & 72.3 \\
\hline Divorced & 30 & 7.5 \\
\hline Widow/Widower & 65 & 16.4 \\
\hline \multicolumn{3}{|l|}{ Educational Qualification } \\
\hline Bachelor's Degree & 262 & 66.0 \\
\hline Master's Degree & 17 & 4.3 \\
\hline Doctoral Degree & 118 & 29.7 \\
\hline \multicolumn{3}{|l|}{ Family' monthly income (Iraqi Dinar) } \\
\hline $300.000-600.000$ & 48 & 12.1 \\
\hline $601.000-900.000$ & 158 & 39.8 \\
\hline $901.000-1.200 .000$ & 100 & 25.2 \\
\hline $1.201 .000-1.500 .000$ & 31 & 7.8 \\
\hline$\geq 1.501 .000$ & 60 & 15.1 \\
\hline
\end{tabular}

Table 2. Association between participants' age, years of employment, body mass index, and their Perceived Susceptibility of contracting colorectal cancer

\begin{tabular}{|c|c|c|c|c|c|}
\hline \multirow[t]{2}{*}{ Model } & \multicolumn{2}{|c|}{ Unstandardized Coefficients } & Standardized & $t$ & Sig. \\
\hline & $B$ & Std. Error & Beta & & \\
\hline Age & .392 & .088 & .323 & 4.467 & .000 \\
\hline Years of employment & -.048 & .106 & -.033 & -.456 & .648 \\
\hline BMI & -.208 & .099 & -.102 & -2.108 & .036 \\
\hline
\end{tabular}

Table 3. Association between participants' age, years of employment, body mass index, and their Perceived Benefits of colorec tal screening

\begin{tabular}{lccccc}
\hline \multicolumn{1}{c}{ Model } & \multicolumn{2}{c}{ Unstandardized Coefficients } & $\begin{array}{c}\text { Standardized } \\
\text { Coefficients }\end{array}$ & $\mathrm{t}$ & Sig. \\
& $\mathrm{B}$ & Std. Error & Beta & & \\
Age & .091 & .062 & .104 & 1.460 & $\mathbf{. 1 4 5}$ \\
\hline Years of employment & -.415 & .075 & -.391 & -5.524 & $\mathbf{. 0 0 0}$ \\
\hline BMI & .222 & .070 & .151 & 3.182 & $\mathbf{. 0 0 2}$ \\
\hline
\end{tabular}

Table 4. Differences in Perceived Barriers to colorectal screening, Perceived Susceptibility of contracting colorectal cancer, and Perceived Benefits of colorectal screening between the gender groups

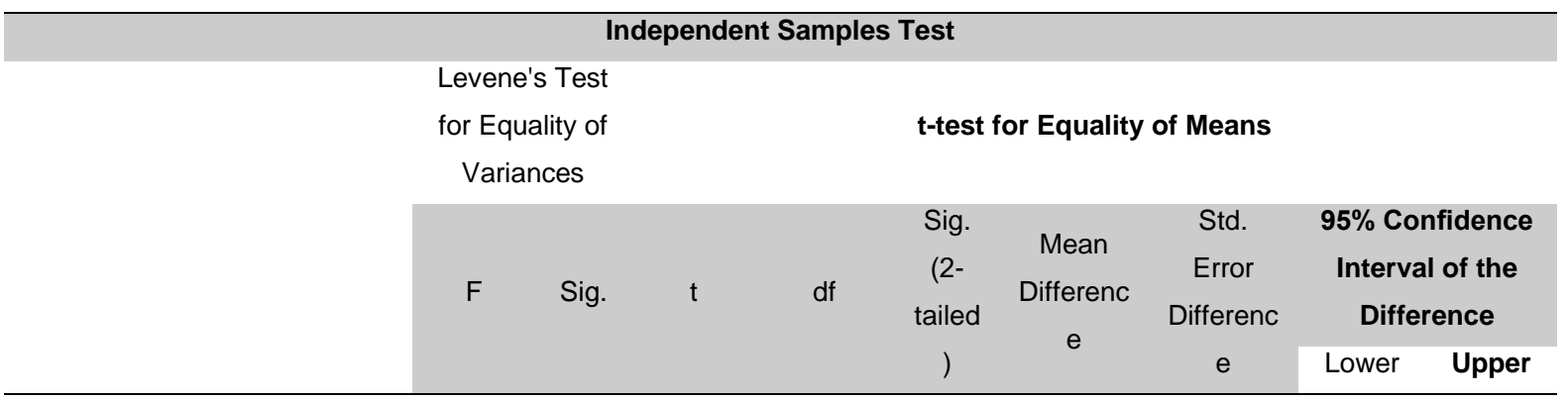




\begin{tabular}{|c|c|c|c|c|c|c|c|c|c|c|}
\hline \multirow{2}{*}{$\begin{array}{c}\text { Perceived } \\
\text { Barriers }\end{array}$} & $\begin{array}{c}\text { Equal } \\
\text { variances } \\
\text { assumed }\end{array}$ & 40.037 & .000 & .884 & 395 & .377 & .86270 & .97637 & $\begin{array}{c}- \\
1.0568 \\
3\end{array}$ & $\begin{array}{c}2.7822 \\
4\end{array}$ \\
\hline & $\begin{array}{c}\text { Equal } \\
\text { variances not } \\
\text { assumed }\end{array}$ & & & .980 & 372.463 & .328 & .86270 & .88024 & $\begin{array}{c}- \\
.86816\end{array}$ & $\begin{array}{c}2.5935 \\
6\end{array}$ \\
\hline \multirow{2}{*}{$\begin{array}{c}\text { Perceived } \\
\text { Susceptibilit } \\
\text { y }\end{array}$} & $\begin{array}{c}\text { Equal } \\
\text { variances } \\
\text { assumed }\end{array}$ & 17.480 & .000 & 4.298 & 395 & .000 & 3.52696 & .82055 & $\begin{array}{c}1.9137 \\
6\end{array}$ & $\begin{array}{c}5.1401 \\
6\end{array}$ \\
\hline & $\begin{array}{c}\text { Equal } \\
\text { variances not } \\
\text { assumed }\end{array}$ & & & 4.630 & 349.806 & .000 & 3.52696 & .76179 & $\begin{array}{c}2.0286 \\
9\end{array}$ & $\begin{array}{c}5.0252 \\
3\end{array}$ \\
\hline \multirow{2}{*}{$\begin{array}{l}\text { Perceived } \\
\text { Benefits }\end{array}$} & $\begin{array}{c}\text { Equal } \\
\text { variances } \\
\text { assumed }\end{array}$ & .336 & .563 & -6.097 & 395 & .000 & -3.52913 & .57884 & $\begin{array}{c}- \\
4.6671 \\
2\end{array}$ & $\begin{array}{c}- \\
2.3911 \\
3\end{array}$ \\
\hline & $\begin{array}{c}\text { Equal } \\
\text { variances not } \\
\text { assumed }\end{array}$ & & & -6.178 & 296.749 & .000 & -3.52913 & .57125 & $\begin{array}{c}- \\
4.6533 \\
5\end{array}$ & $\begin{array}{c}- \\
2.4049 \\
1\end{array}$ \\
\hline
\end{tabular}

Table 5. Differences in Perceived Barriers to colorectal screening, Perceived Susceptibility of contracting colorectal cancer, and Perceived Benefits of colorectal screening between the family history of colorectal cancer groups

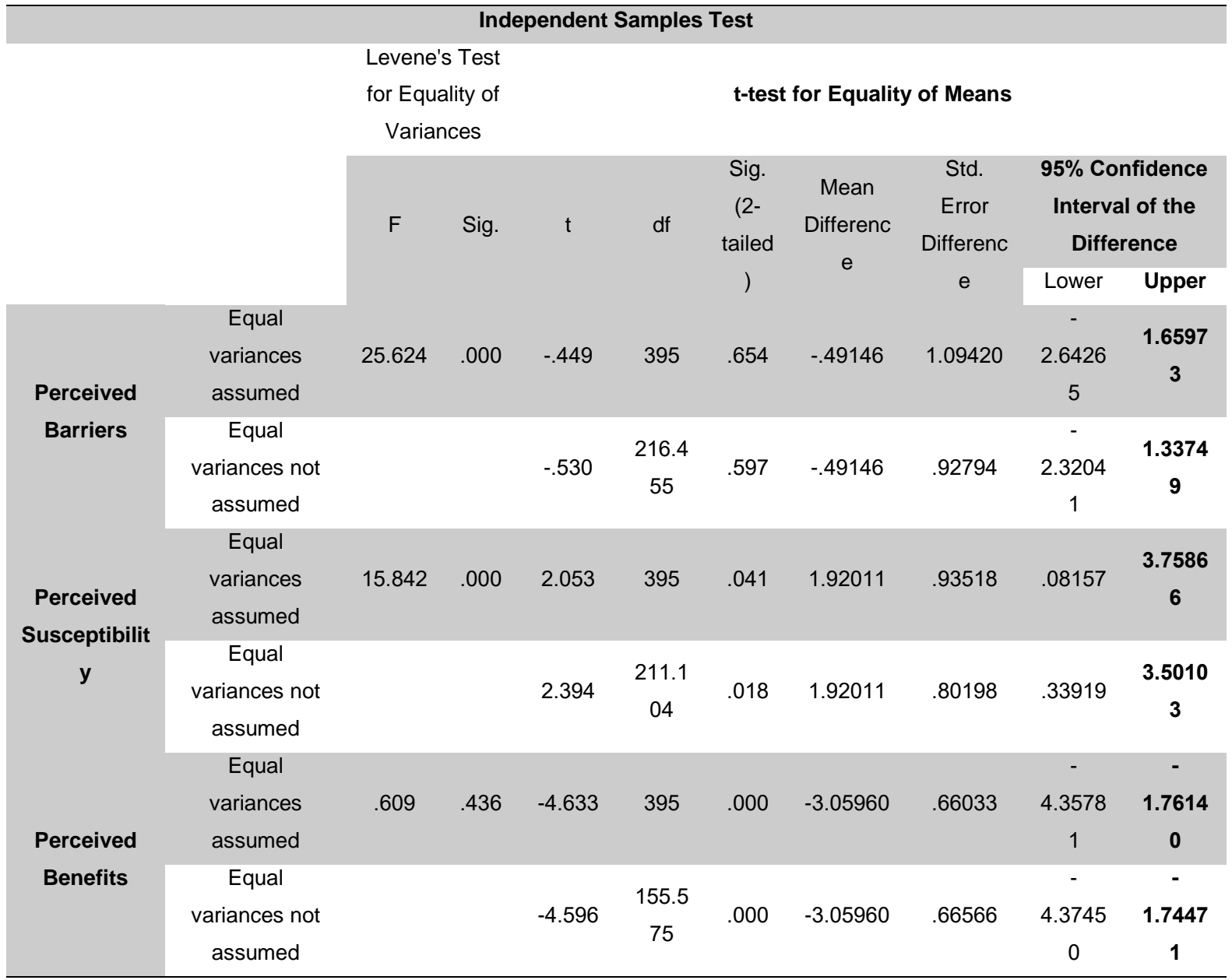


Table 6. Differences in Perceived Barriers to colorectal screening, Perceived Susceptibility of contracting colorectal cancer, and Perceived Benefits of colorectal screening among the marital status groups

\begin{tabular}{|c|c|c|c|c|c|c|}
\hline \multicolumn{7}{|c|}{ ANOVA } \\
\hline & & Sum of & $d f$ & Mean & $\mathrm{F}$ & Sig. \\
\hline & & Squares & & Square & & \\
\hline \multirow[t]{3}{*}{ Perceived Barriers } & Between Groups & 1530.283 & 3 & 510.094 & 6.137 & .000 \\
\hline & Within Groups & 32664.140 & 393 & 83.115 & & \\
\hline & Total & 34194.423 & 396 & & & \\
\hline \multirow{3}{*}{$\begin{array}{c}\text { Perceived } \\
\text { Susceptibility }\end{array}$} & Between Groups & 1451.247 & 3 & 483.749 & 7.995 & .000 \\
\hline & Within Groups & 23779.750 & 393 & 60.508 & & \\
\hline & Total & 25230.997 & 396 & & & \\
\hline \multirow[t]{3}{*}{ Perceived Benefits } & Between Groups & 682.974 & 3 & 227.658 & 7.192 & .000 \\
\hline & Within Groups & 12440.457 & 393 & 31.655 & & \\
\hline & Total & 13123.431 & 396 & & & \\
\hline
\end{tabular}

Table 7. Differences in Perceived Barriers to colorectal screening, Perceived Susceptibility of contracting colorectal cancer, and Perceived Benefits of colorectal screening among the educational qualification groups

\begin{tabular}{|c|c|c|c|c|c|c|}
\hline \multicolumn{7}{|c|}{ ANOVA } \\
\hline & & Sum of & $d f$ & Mean & $\mathrm{F}$ & Sig. \\
\hline & & Squares & & Square & & \\
\hline \multirow[t]{3}{*}{ Perceived Barriers } & Between Groups & 3860.651 & 2 & 1930.326 & 25.073 & .000 \\
\hline & Within Groups & 30333.772 & 394 & 76.989 & & \\
\hline & Total & 34194.423 & 396 & & & \\
\hline \multirow{3}{*}{$\begin{array}{c}\text { Perceived } \\
\text { Susceptibility }\end{array}$} & Between Groups & 255.231 & 2 & 127.616 & 2.013 & .135 \\
\hline & Within Groups & 24975.766 & 394 & 63.390 & & \\
\hline & Total & 25230.997 & 396 & & & \\
\hline \multirow[t]{3}{*}{ Perceived Benefits } & Between Groups & 371.858 & 2 & 185.929 & 5.745 & .003 \\
\hline & Within Groups & 12751.573 & 394 & 32.364 & & \\
\hline & Total & 13123.431 & 396 & & & \\
\hline
\end{tabular}

\section{DISCUSSION}

This descriptive predictive study aimed mainly to predicts the factors that determine subjects' intention to perform colorectal screening. There was a statistically significant inverse association between participants' years of employment and their Perceived Benefits of colorectal screening. This finding could be explained as younger subjects recognize that their likelihood of contracting colorectal cancer would be lesser compared to those who are older. That is, they would not benefit as much of performing colorectal screening as those who are older.

On the other hand, there is a statistically significant positive association between participants' body mass index and their Perceived Benefits of colorectal screening. This finding could be explained as subjects who are overweight or obese could recognize that their current body weight increases the likelihood of contracting colorectal cancer.
There was a statistically significant difference subjects' Perceived Susceptibility of contracting colorectal cancer between the groups of gender. Further descriptive statistics demonstrate that the value of the Perceived Susceptibility of contracting colorectal cancer is greater among male subjects. This finding could be explained as male subjects could sensitize a greater likelihood of contracting colorectal cancer compared to female subjects.

Martinelli et al., (2014) concluded that there is a significant association was observed with carcinoma of the sigmoid colon, and with CRC in the male strata. In the same line, Zucchin et al., (2015) concluded that there was no statistically significant association between variant alleles and the occurrence of colorectal cancer or with regional lymph node metastasis for any of the studied genes; however, there was a statistically significant association between colorectal cancer occurrence and gender in favor of males.

There was a statistically significant difference subjects' Perceived Benefits of colorectal cancer screening between the groups of gender. Further descriptive statistics demonstrate that the value 
of the Perceived Benefits of performing colorectal cancer screening is greater among female subjects compared to male subjects. This finding almost goes in line with that of Zheng et al., (2006) who concluded that gender had significant association with the Perceived Benefits of colorectal cancer screening.

There was a statistically significant difference in subjects' Perceived Susceptibility of contracting colorectal cancer between the family history of colorectal cancer. Further descriptive statistics demonstrate that the value of the Perceived Susceptibility of contracting colorectal cancer was greater among subjects who reported that they have a family history of colorectal cancer. This finding could be explained as subjects who reported that they have a family history of colorectal cancer view colorectal cancer as more fatal compared to subjects who do not have such a history. According the Health Belief Model, the family history of a given disease represents one of the modifying factors that could shape individuals' health behavior (performing colorectal cancer screening). However, Zheng et al., (2006) concluded that having a family history of colorectal cancer could triggering an individual to who one of the critiques on the Health Belief Model is it didn't exactly demonstrate how the modifying variable ca shape an individual's health behavior. However, family history (Glanz et al., 2015).

There was a statistically significant difference in subjects' Perceived Benefits of colorectal screening between the family history of colorectal cancer. This finding could be explained in the context of the Health Belief Model which postulates that the Perceived Benefits would be the main trigger for individuals who contracted a specific disease or health condition to adopt a healthy behavior "colorectal cancer screening"

This finding is supported by Zheng et al., (2006) who concluded that the value of the Perceived Benefits was greater among subjects with a family history of colorectal cancer.

The was a statistically significant difference in subjects' Perceived Barriers to colorectal screening among the marital status groups. Further post hoc analysis demonstrates that the value of the Perceived Barriers to colorectal screening is greater among married individuals. This finding could be explained as married individuals may believe that contracting colorectal cancer threats their life and their families' life. On the other hand, they may believe that performing colorectal screening would be extremely beneficial when it performed at an early stage in detecting a potential colorectal cancer and prevent its devastating course. This finding is consistent with that of Lemeshow and Paskett (2008) who concluded that higher screening rates were observed in married participants $(41.8 \%)$ compared to those not married. On the other hand, this finding is inconsistent with that of Tekiner et al., (2021) who concluded that there was a statistically difference the Perceived Barrier score the married and single participants where it was significantly higher in single subjects than in married subjects.

The was a statistically significant difference in subjects' Perceived Susceptibility of contracting colorectal cancer among the marital status groups. Further post hoc analysis demonstrates that the value of the Perceived Susceptibility of contracting colorectal cancer is greater among single individuals.

\section{CONCLUSIONS}

Male subjects believe in a greater likelihood of contracting colorectal cancer than female subjects.

Subjects who have a family history of colorectal cancer believe in a greater likelihood of contracting colorectal cancer than those who do not have such a history.

Married subjects encounter greater obstacles to undergo colorectal screening.

Single subjects believe in a greater likelihood of contracting colorectal cancer.

Married subjects believe in worth of undergoing colorectal screening.

The lower the educational qualification, the greater the encountered barriers to colorectal screening vice versa.

The higher the educational qualification, the greater Perceived Benefits to colorectal screening.

The greater the body mass index, the greater the Perceived Barriers to colorectal screening.

The poorer the monthly income, the greater the Perceived Barriers to colorectal screening.

The better the monthly income, the greater the Perceived Susceptibility to colorectal screening.

\section{RECOMMENDATIONS}

There is a need to devote health promotion activities, particularly that encourage older teachers, those who are overweight and/or obese, those who have a family history of colorectal cancer, single, and have lower educational qualification to undergo colorectal screening.

There is a need to incorporate health education materials into curricula of different educational level that shed the light on healthy behaviors related colorectal health

\section{ETHICAL CONSIDERATIONS COMPLIANCE WITH ETHICAL GUIDELINES}

This study was obtained from the College of Nursing, University of Baghdad, Iraq. The participants were informed about the research's purpose and ensured anonymity and confidentiality of the information. A written informed, voluntary participation consent was obtained from each participant.

\section{FUNDING}

This research did not receive any grant from 
funding agencies in the public, commercial, or non-profit sectors.

\section{AUTHOR'S CONTRIBUTIONS}

Study concept, Writing the original draft, Data collection, Data analysis, Reviewing the final edition: by all authors.

DISCLOSURE STATEMENT: The authors report no conflict of interest.

\section{ACKNOWLEDGEMENTS}

We thank the anonymous referees for their useful suggestions.

\section{REFERENCES}

Abd Ali, M. B. (n.d,). Psychometric properties of the Arabic version of the Transtheoretical Model of Change for Fruits and Vegetables Consumption. Unpublished paper.

Abraham, S. and Sheeran, P. (2014). The Health Belief Model. In Cambridge handbook of psychology, health and medicine, Second Edn, 97102.

Campos F. G. (2017). Colorectal cancer in young adults: A difficult challenge. World journal of gastroenterology, 23(28), 5041-5044. https://doi.org/10.3748/wjg.v23.i28.5041

Fancher, T. T., Palesty, J. A., Rashidi, L., \& Dudrick, S. J. (2011). Is gender related to the stage of colorectal cancer at initial presentation in young patients?. The Journal of surgical research, 165(1), 15-18. https://doi.org/10.1016/j.jss.2010.08.054 He, L., Gao, S., Tao, S., Li, W., Du, J., Ji, Y., \& Wang, Y. (2020). Factors associated with colonoscopy compliance based on Health Belief Model in a community-based colorectal cancer screening program Shanghai, China. International Quarterly of Community Health Education, 41(1), 25-33.

Hubbard, J. M., \& Grothey, A. (2013). Adolescent and young adult colorectal cancer. Journal of the National Comprehensive Cancer Network : JNCCN, 11(10),

1219-1225.

https://doi.org/10.6004/jnccn.2013.0144

Khani Jeihooni, A., Kashfi, S. M., Shokri, A., Kashfi, S. H., \& Karimi, S. (2017). Investigating Factors Associated with FOBT Screening for Colorectal Cancer Based on the Components of Health Belief Model and Social Support. Asian Pacific Journal of Cancer Prevention : APJCP, 18(8), 2163-2169. https://doi.org/10.22034/APJCP.2017.18.8.2163 Loomans-Kropp, H. A., \& Umar, A. (2019). Increasing Incidence of Colorectal Cancer in Young Adults. Journal of Cancer Epidemiology, 2019, 9841295. https://doi.org/10.1155/2019/9841295
Martinelli, M., Scapoli, L., Cura, F., Rodia, M. T., Ugolini, G., Montroni, I., \& Solmi, R. (2014). Colorectal cancer susceptibility: Apparent genderrelated modulation by $A B C B 1$ gene polymorphisms. Journal of Biomedical Science, 21, 89.

Orji, R., Vassileva, J., \& Mandryk, R. (2012). Towards an effective health interventions design: an extension of the health belief model. Online journal of public health informatics, 4(3), ojphi.v4i3.4321.

https://doi.org/10.5210/ojphi.v4i3.4321

Siegel, R. L., Miller, K. D., \& Jemal, A. (2019). Cancer statistics, 2019. CA: a cancer journal for clinicians, 69(1), 7-34. https://doi.org/10.3322/caac.21551

Tahmasebi, R., Noroozi, A., \& Dashdebi, K. G. (2016). Psychometric evaluation of the Colorectal Cancer Screening Belief Scale based on Health Belief Model's constructs for the fecal occult blood test. Asian Pacific Journal of Cancer Prevention: APJCP, 17(1), 225-229.

Tekiner, S., Peker, G. C., \& Doğan, M. C. (2021). Colorectal cancer screening behaviors. PeerJ, 9, e10951.

Vuik, F. E., Nieuwenburg, S. A., Bardou, M., Lansdorp-Vogelaar, I., Dinis-Ribeiro, M., Bento, M. J., Zadnik, V., Pellisé, M., Esteban, L., Kaminski, M. F., Suchanek, S., Ngo, O., Májek, O., Leja, M., Kuipers, E. J., \& Spaander, M. C. (2019). Increasing incidence of colorectal cancer in young adults in Europe over the last 25 years. Gut, 68(10), 18201826. https://doi.org/10.1136/gutjnl-2018317592

Williams, R. M., Wilkerson, T., \& Holt, C. L. (2018). The role of perceived benefits and barriers in colorectal cancer screening in intervention trials among African Americans. Health Education Research, 33(3), 205-217.

Zheng, Y.-F., Saito, T., Takahashi, M., Ishibashi, T., \& Kai, I. (2006). Factors associated with intentions to adhere to colorectal cancer screening follow-up exams. BMC Public Health, 6, 272.

Zucchini, C., Martinelli, M., De Sanctis, P., Rodia, M. T., Mattei, G., Ugolini, G., Montroni, I., Ghignone, F., \& Solmi, R. (2015). Possible GenderRelated Modulation by the ROCK1 Gene in Colorectal Cancer Susceptibility. Pathobiology: Journal of Immunopathology, Molecular and Cellular Biology, 82(6), 252-258. 